\title{
OVERVIEW OF BOVINE DENDRITIC CELLS
}

\author{
Lucie Kratochvílová, Petr Sláma ${ }^{1}$ \\ ${ }^{1}$ Department of Animal Morphology, Physiology and Genetics, Faculty of AgriSciences, Mendel University in \\ Brno, Zemědělská 1, 61300 Brno, Czech Republic
}

\begin{abstract}
KRATOCHVÍLOVÁLUCIE, SLÁMAPETR. 2018. Overview of Bovine Dendritic Cells. Acta Universitatis Agriculturae et Silviculturae Mendelianae Brunensis, 66(3): 815-821.

This article is an overview of dendritic cells (DCs) in cattle. The understanding of the immune system and the role of DCs in many ways can contribute to their use in the prevention and treatment of many infectious and autoimmune diseases. DCs are bone marrow-derived cells that function as professional antigen presenting cells. They act as messengers between the innate and the adaptive immune systems. The morphology of DCs results in a very large surface to volume ratio. That is, the DCs have a very large surface area compared to the overall cell volume. Currently, most dendritic cells research occurs in the human and mice. There is a lack of studies in cattle describing DCs. DCs survey the body and collect information relevant to the immune system. They are then able to instruct and direct the adaptive arms to respond to challenges.
\end{abstract}

Keywords: dendritic cell, cattle, mammary gland, mastitis, Langerhans cell

\section{INTRODUCTION}

Dendritic cells (DCs) are antigen presenting cells, which capture microbial antigens that enter from the external environment, transport these antigens to lymphoid organs, and present the antigens to naive $\mathrm{T}$ lymphocytes to initiate immune responses (Abbas et al., 2014). DCs provide communication between innate and adaptive immune systems. DCs are present in most tissues and are concentrated in lymphoid organs and in interfaces with the external environment, such as the skin (there is a specialized DCs type also called the Langerhans cell) and the gastrointestinal and respiratory tracts and blood. During certain stages of development, DCs develop branched projections called "dendrites", which is why they are so named.

First to describe DCs was Paul Langerhans in 1868. DCs were first identified in mice by Steinman and Cohn in 1973, and were shown to represent a heterogeneous population distributed in lymphoid and nonlymphoid tissues throughout the body (Ardavin et al., 1993; Austyn et al., 1994).

These cells are the aim of investigation in many laboratories due to their role as adjuvants for vaccines that prevent microbial infections and treat cancer (De Smedt et al., 1996; Kirschner, 2006; Steinmann, 1991). They not only have an enhancing effect on the acquired immunity development, but can induce tolerance and can likely be manipulated to prevent and treat allergic and autoimmune diseases. DCs play an important role in the pathogenesis of viral infections human immunodeficiency virus (HIV) and they might also be directed to enhance immunisation procedures (Werling et al., 1999; Yamanaka et al., 2005). DCs should be targeted by DNA vaccination (Condon et al., 1996).

The phenotype and functions of DCs are best known in humans and mice, however this overview is focused on the DCs in cattle.

\section{Life cycle of dendritic cells}

Dendritic cells are formed from hematopoietic progenitor cells in the bone marrow (Banchereau and Steinman, 1998). Initially, the progenitor cells form immature DCs which have the endocytic capability but a low capacity to stimulate $\mathrm{T}$ cells (Mandal, 2014). These immature cells monitor their environment for invaders such as bacteria and viruses, which they achieve through pattern recognition receptors (PRRs) such as toll-like receptors (TLRs) (Syme and Gluck, 2001).

As soon as these immature cells meet a presented antigen, they mature and move towards the lymph nodes. The immature dendritic cell engulfs the pathogen and breaks down its proteins, which it presents on its surface using major histocompatibility 
complex (MHC) molecules once it matures (Mandal, 2014). At the same time, the cell-surface receptors that act as co-receptors in T-cell activation are upregulated by DCs (Abbas et al., 2014). Furthermore, the chemokine receptor (CCR) 7 is also upregulated. This chemotactic receptor induces the movement of dendritic cells through the blood and towards the spleen or lymph node where they activate T cells and B cells through antigen presentation. Activated macrophages have a lifespan of a few days, lifespan of activated DCs is similar. However, it appears that immature dendritic cells can remain in their inactivated state for significantly longer periods of time (Mandal, 2014).

DCs can also develop from $\mathrm{CD}^{+} 4^{+}$peripheral blood monocytes cultured with granulocyte macrophage colony-stimulating factor (GM-CSF) and interleukin (IL) 4 (Sallusto and Lanzavecchia, 1994). Under this culture conditions monocytes develop into a homogenous population of DCs without dividing (Cella, 1997). These cells have the characteristics of immature DCs and can be further induced to mature by inflammatory stimuli such as tumor necrosis factor $\alpha(\mathrm{TN}-\mathrm{F} \alpha)$, IL-1 or lipopolysaccharide (LPS) (Sallusto and Lanzavecchia, 1994) or by monocyte conditioned medium (Romani et al., 1996). It is interesting that immature DCs generated from monocytes still retain the monocyte colony-stimulating factor (M-CSF) receptor, although they lose it following induction of maturation (Romani et al., 1996). Thus, the emerging concept is that monocytes represent an abundant source of precursors that can polarize towards DCs or macrophages, depending on the external stimuli. This polarization can be driven in vitro by the addition of appropriate cytokines (GM-CSF, IL-4 or M-CSF) (Cella, 1997).

\section{Types of dendritic cells}

DCs are heterogeneous cells that can be divided into the few functionally-distinct subsets on the basis of their phenotype, the possibility of migration and the ability for cytokine production, that modulate both innate and adaptive immune response (Sato and Fujita, 2007). Dendritic cells can be classified into two major cell subsets: classical DCs (also called conventional DCs) and plasmacytoid DCs. Classical DCs have the ability to stimulate strong $\mathrm{T}$ cell responses, and are the most numerous DCs subset in lymphoid organs. Most of them are derived from myeloid precursors, which migrate from the bone marrow to differentiate locally into resident dendritic cells in lymphoid and non-lymphoid tissues. Like tissue macrophages, they constantly sample the environment in which they reside. In the intestine, for example, DCs appear to send out processes that traverse the epithelial cells and project into the lumen, where they may act to capture luminal antigens. Langerhans cells are the dendritic cells that populate the epidermis; they serve the same role for antigens encountered in the skin. In the absence of infection or inflammation, classical dendritic cells capture tissue antigens and migrate to the draining lymph nodes but do not produce cytokines and membrane molecules that are required to induce effective immune responses. The function of these dendritic cells may be to present self-antigens to self-reactive $\mathrm{T}$ cells and thereby cause inactivation or death of the $\mathrm{T}$ cells or generate regulatory $\mathrm{T}$ cells. These mechanisms are important for maintaining self-tolerance and preventing autoimmunity responses (Abbas et al., 2014). On an encounter with microbes or cytokines, the DCs become activated: they upregulate costimulatory molecules, produce inflammatory cytokines, and migrate from peripheral tissues into draining lymph nodes, where they initiate $\mathrm{T}$ cell responses.

Classical DCs may be divided into two major subsets. One, identified by high expression of BDCA-l/CDlc in humans or the CDllb integrin in mice, is most potent at driving $\mathrm{CD}^{+} \mathrm{T}$ cell responses. The other subset, identified by expression of BDCA-3 in humans or, in mice, CD8 in lymphoid tissues or the $\mathrm{CDl03}$ integrin in peripheral tissues, is particularly efficient in the process of cross-presentation. Some DCs may be derived from monocytes, especially in situations of inflammation (Abbas et al., 2014).

Plasmacytoid DCs resemble plasma cells morphologically and acquire the morphology and functional properties of DCs only after activation. Plasmacytoid DCs develop in bone marrow. They are found in the blood and in lymphoid organs (Abbas et al., 2014). In contrast to classical DC, plasmacytoid DC are poorly phagocytic and do not sample environmental antigens. Plasmacytoid DC representing the most potent type I interferon (IFN) producing cell, able to efficiently sense microbial nucleic acid (Liu, 2005).

DCs in blood are typically identified and enumerated in flow cytometry. There are three types of DCs in blood: $\mathrm{CDlc}^{+}$myeloid DCs, $\mathrm{CD} 41^{+}$myeloid and $\mathrm{CD} 33^{+}$plasmacytoid DCs (Ziegler-Heitbrock et al., 2010).

\section{Bovine dendritic cells}

The bovine species is an interesting model for the study of the immune system mainly because of its size that eases the chirurgical access to the blood and lymph vessels (De Carvalho et al., 2006). Two models were used to investigate DCs in cattle. The cannulation of pseudo afferent lymphatic ducts after surgical removal of the pre-scapular lymph node, originally described in sheep, were applied to cattle studies (Emery et al., 1987). This allows access to DCs that are draining from the skin that have not been extensively cultivated in vitro which should represent DCs ex vivo that are closely related in their properties to cells in vivo (Howard et al., 1999). Studies in humans showed that monocytes cultured in the presence of GM-CSF and IL-4 acquired many of the properties of DCs (Sallusto et al., 1995). This monocyte derived DCs (MoDC) have been 
shown to be highly effective at stimulating $\mathrm{T}$ cell responses and in the uptake and processing and presentation of antigen (Howard et al., 1999). Such cells are readily available as autologous cells for in vitro investigations. They provide a further valuable model that does not involve the use of prolonged isolation procedures (Howard et al., 1999). Methods to isolate sparse DCs were originally described to derive DCs from human blood and have been adapted to cattle (Renjifo et al., 1997), but produce only small numbers of cells which restricts their potential for investigation (Howard et al., 1999). The cattle is an animal model for some human pathologies as the bovine respiratory syncytial virus (BRSV), Creutzfeldt-Jacob disease, Crohn's disease, $\mathrm{T}$ cell leukaemia and rotavirus diarrhoea (Hein and Griebel, 2003). Bovine DCs isolated from lymph were characterized phenotypically and functionally (Mc Keever, 1991). The generation of DCs from bovine blood monocytes was described (Werling et al., 1999). Bovine DCs were obtained from bone marrow cells cultured with GM-CSF and IL4 (Hope et al., 2000). The immune-phenotype of DCs from cattle was: $\mathrm{CDI}^{\text {high }}$, MHC class $\mathrm{II}^{\text {high }}$, CD80high, CD86 ${ }^{\text {high }}, \mathrm{CD} 1 \mathrm{a}^{\text {high }}$, CDllb ${ }^{\text {intermediate }}$, CDIlc low and CD14 ${ }^{\text {low }}$ (De Carvalho et al., 2006). DCs generated from monocytes expressed CD14 and CDllb (Howard et al., 1999). DCs of cattle are very good described in the afferent lymph, in which two subsets were described: a major $\mathrm{CD} b^{\text {high }} \mathrm{CD} 11 \mathrm{a}^{-} \mathrm{CD} 13^{-} \mathrm{CD} 26^{-} \mathrm{CD} 172 \mathrm{a}^{+}$subset and a minor $\mathrm{CD} \mathrm{b}^{\text {low }} \mathrm{CD} 1 \mathrm{a}^{+} \mathrm{CD} 13^{+} \mathrm{CD} 26^{+} \mathrm{CD} 172 \mathrm{a}^{-}$ subset (McKeever et al., 1992; Howard et al., 1997; Howard et al., 1999; Gliddon and Howard, 2002; Summerfield et al., 2015). Studies in cattle have shown that the DCs are phenotypically heterogeneous and that the different phenotypes, related to their stage of maturation correspond to different biological properties (De Carvalho et al., 2006).

Bovine DCs are divided into three groups: bone marrow derived (BMDC/myeloid/conventional derived), monocyte related (MoDC, $\mathrm{CDI} 4^{+}$) and tissue resident (anatomical location).

During differentiation of monocytes into MoDC, CD1b, CD205, and CD206 are upregulated, but CD1lc, CD14 and CD62L are downregulated (Werling et al., 1999; Bajer et al., 2003; Mackenzie-Dyck et al., 2011; Summerfield et al., 2015). Bovine monocyte derived DCs express myeloid markers (CDlla, CDllb, CD14 and CD172a) and when activated the expression levels of CD40, CD80 and CD86 are up-regulated.

Bovine DCs differ phenotypically based on their tissue distribution. MHC II expression detects DCs of hematopoietic origin; CD $208^{+}$DCs are found in lymphoid tissues and $\mathrm{CDIb}^{+}$expressing DCs are mainly found in the thymic medulla (Romero-Palomo et al., 2013).

Bovine plasmacytoid DCs are still not as well characterized as human and mouse ones but researchers have shown that they express MHC II, CD4, CD172a, CD32, and CD45RB and produce very high levels of type I interferons in response to viral infections (e.g. foot and mouth disease (FMDV)) (Reid et al., 2011).

Expression of the myeloid specific marker CD172a has also been used to identify the tissue distribution of bovine DCs (Miyazawa et al., 2006; Sei et al., 2014). MHC II, CDIlc, and CD172a being expressed on peripheral blood DCs; CDI and CD172a on DCs in the thymic medulla and CDIlb and CD172a on DCs within the Peyer's patches (Brimczoket al., 2005).

The finding that some of the Peyer's patches DCs express the prion protein $(\operatorname{Pr} \mathrm{P})$ could indicate that these DCs may be involved in the transmission of bovine spongiform encephalopathy (BSE) (Rybner-Barnier C et al., 2006).

The differential expression of MHC II, CD208 (DC-LAMP), CD1b, CD205 (DEC-205), CNA.42 and S100 protein on DCs further helps to define DC subtypes. There are also special types of DCs as interdigitating DCs and follicular DCs (FDA DC). CD208 is expressed on interdigitating DCs present in the thymic medulla and within the Peyer's patches follicles. CD1b identifies thymic DCs and CD205 is strongly expressed on afferent lymph DCs (ALDC). Bovine follicular dendritic cells can be identified by their expression of both CNA.42 and S100.

Bovine peripheral blood DCs express CD80 and have been shown to consist of three different subsets (Sei et al., 2014):

- immature CD4 ${ }^{+}$MHC II - pDCs that upon TLR stimulation upregulate their MHC II and CD80 expression and produce large amounts of type I interferons; (DCs express TLR7 and TLR9) and

- twocDCtypesthatexpressMHCIIbuthavedifferent functional markers, cytokine profiles and antigen processing abilities: $\mathrm{CD} l \mathrm{lc}+\mathrm{MHC}{ }^{\mathrm{II}}+\mathrm{CD}^{80 h i g h}$ DCs (may be specialized in naive $\mathrm{T}$ cell activation expression) that produce TNF- $\alpha$ and have antigen processing abilities; and CDllc-MHC $\mathrm{II}^{+}$DCs which are precursors of CDllc $\mathrm{c}^{+}$DCs (Sei et al., 2014). DCs are important in supporting the initiation of an immune response. These cells traffic into affected mucosal tissues following infection with mycobacteria and generate the induction and maintenance of an immune response at the mucosal surfaces. DCs can provide positive signals for the induction of immunity versus mycobacteria. Bovine DCs can induce the proliferation of mycobacteria-specific CD $4^{+}$and $\mathrm{CD}^{+} \mathrm{T}$ cells.

Bovine macrophages and DCs are permissive for Mycobacterium bovis replication. They have the different role in bovine mycobacterial infections. DCs induce T-cell proliferation and activation whereas macrophages are primarily involved in curtailing bacterial replication and providing proinflammatory signals that promote the continual recruitment of inflammatory cells. The development of new generations of vaccines against bovine tuberculosis should elicit activation of DCs to stimulate maximal antigen presentation of IL-12 and a robust protective T-cell response, in concert with an appropriate macrophage activation 
profile, to fully restrict bacterial replication (Denis and Buddle, 2008).

DCs produce IL-12 and pro-inflammatory cytokines upon mycobacterial infection, important for orientation towards a Thl response to control disease. However, it has been demonstrated that different APC (macrophages and DC) react differently to the same stimulus. With regard to cytokines, macrophages react primarily by IL-10 production, while DCs produce mainly IL-12 upon infection with Mycobacteria tuberculosis.

There is no reliable method established for the isolation of bovine peripheral blood DCs, and furthermore, the phenotypes and the functions of bovine DCs are still not fully clear. The regulation of humoral immune responses in cattle depends on the origin of DCs and the mode of B cell activation (Pinchuk, 2003).

\section{Dendritic cells and mastitis}

Many different bacterial species can cause an infection of the bovine mammary gland. The host response to these infections is what we recognize as mastitis. Mastitis is a highly prevalent disease in dairy cows and economically costly to the dairy industry worldwide (Bannerman, 2009). Clinical mastitis (CM) is characterized by visible changes in milk from the gland including the presence of clots, heat, pain or swelling of a gland. CM is generally caused by an intermammary infection (IMI) with a bacterial pathogen. Staphylococcal, streptococcal and Gram-negative bacterial species are general bacterial causes of mastitis (OldeRiekerink et al., 2008; Barkema et al., 1998). Although intramammary infections occur at any time during the life cycle of the adult dairy cow, there is a predominance of clinical mastitis cases in early lactation (Barkema et al., 1998).

The innate defence mechanisms of the mammary gland include physical barriers such as the teat sphincter, chemical barriers such as teat canal keratin and lactoferrin, and more proper components of the immune system such as macrophages, DCs, mast cells, neutrophils, eosinophils and natural killer (NK) cells (Werling et al., 2006). The first and mandatory step in the immune defence against the invading pathogen is recognition of pathogen. Mammals are equipped by receptors which recognize pathogens for instance toll-like receptors (TLRs) (Schukken et al., 2013). TLR signal transduction pathways activate transcription factors such as TNF, interferon (IFR) and activating protein-1 (AP1) (Akira and Takeda, 2004). DCs are major antigen presenting cells in the mammary gland. Recognition and uptake of antigen at the site of infection induces maturation of the DC (Della Chiesa et al., 2005) and homing to the supramammary lymph nodes (Maxymiv et al., 2012) where DCs present the antigen to naive T cells. Activated DCs express high levels of antigen-MHC complexes, secrete cytokines, and upregulate co-stimulatory surface molecules such as CD40 and B-7 molecules, all which as necessary signals to induce and influence $\mathrm{T}$ cell activation and differentiation; in lactating cows, high levels of IL-12 secretion has been suggested to promote Thl differentiation (Schukken et al., 2013). IL-12 produced by DC also induces IFN $\gamma$ production by other innate immune cells include NK cells thereby contributing to immediate pro-inflammatory responses (Schukken et al., 2013). A predominant Thl response results in a pro-inflammatory response, where production of pro-inflammatory cytokines results in a massive influx of polymorphonuclear cells that aim to kill the invading organisms (Schukken et al., 2013).

Pregnancy presents a major challenge to the maternal immune system, both in normal and pathologic states (Denney et al., 2011). The immune response is modulated to allow establishment and maintenance of a viable pregnancy without rejection (Schukken et al., 2013). Progesterone in concentrations present during pregnancy is a potent inducer of the Thl cytokines IL-4. A Th2 shift in pregnancy is also characterized by the reduction in IFN- $\gamma$ and IL-2 producing $\mathrm{CD}^{+}$and $\mathrm{CD}^{+} \mathrm{T}$ cells (Raghupathy, 2001). Circulating pregnancy factors including progesterone and estrogens impact DC activation by impairing cytokine production and surface marker expression found necessary for $\mathrm{T}$ cell activation and Thl differentiation, and induction of IFN $\gamma$ production in other innate immune cell populations. The dominant Th2 response results in a limited inflammatory response and in most cases no signs of clinical mastitis will be the result of an intramammary infection (Schukken et al., 2013).

\section{CONCLUSION}

Dendritic cells were described in cow and several other species. Further understanding DCs and related processes can contribute to the development of new treatments and open new opportunities for research such as organ transplantation, immunotherapy and treatment of mastitis in animals. DCs have potential in treatment of many infectious, allergic and autoimmune disease too. This paper provided an overview of DCs in cattle. The better understanding of DCs biology in number of species is important for their practical application in animal breeding. 


\section{REFERENCES}

ARDAVIN, C., WU, L., LI, C. L. and SHORTMAN, K. 1993. Thymic dendritic cells and T cells develop simultaneously in the thymus from a common precursor population. Nature, 362(6422): 761-763.

AUSTYN, A. M., HANKINS, D. F., LARSEN, C. P., MORRIS, P. J. and ROAKE, J. A. 1994. Isolation and characterization of dendritic cells from mouse heart and kidney. Journal of Immunology, 152 (5): 2401-2410.

ABBAS, K., LICHMAN, A. and PILLAI S. 2014. Cellular and molecular immunology. $7^{\text {th }}$ Edition. Philadelphia: Saunders/Elsevier.

AKIRA, S. and TAKEDA, K. 2004. Toll-like receptor signalling. Nature Reviews Immunology, 4(7): 499-511.

BAJER, A. A., GARCIA-TAPIA, D., JORDAN, K. R., HAAS, K. M. and WERLING, D. 2003. Peripheral blood-derived bovine dendritic cells promote IgGl-restricted B cell response in vitro. Journal of Leukocyte Biology, 73: 100-106.

BANNERMAN, D. D. 2009. Pathogen-dependent induction of cytokines and other soluble inflammatory mediators during intramammary infection of dairy cows. Journal of Animal Sciences, 87(Suppl.1): 10-25.

BARKEMA, H. W., SCHUKKEN, Y. H., LAM T. J., BEIBOER M. L., WILMINK, G. BENEDICTUS, G. and BRAND, A. 1998. Incidence of clinical mastitis in dairy herds grouped in three categories by bulk milk somatic cell counts. Journal of Dairy Science, 81(2): 411-419.

BANCHEREAU, J. and STEINMAN, R. M. 1998. Dendritic cells and the control of immunity. Nature, 392(6673): 245-252.

BRIMCZOK, D. 2003. Site-specific expression of CDllb and SIRPalpha (CD172a) on dendritic cells: implications for their migration patterns in the gut immune system. European Journal of Immunology, 35(5):1418-1427.

CONDON, C., WATKINS, S. C., CELLUZZI, C. M., THOMPSON, K. and FALO JR., L. D. 1996. DNA-based immunization by in vivo transfection of dendritic cells. Nature Medicine, 2: 1122-1128.

COURREGES, M. C., BURZYN, D., NEPOMNASCHY, I., PIAZZON, I. and ROSS, S. R. 2007. Critical role of dendritic cells in mouse mammary tumor virus in vivo infection. Journal of Virology, 81(8): 3769-3777.

CELLA, M., SALLUSTO, F. and LANZAVECCHIA, A. 1997. Origin, maturation and antigen presenting function of dendritic cells. Current Opinion in Immunology, 9(1): 10-16.

DE CARVALHO, C. M., BONNEFONT-REBEIX, C., RIGAL, D. and CHABANNE, L. 2006. Dendritic cells in different animal species: an overview. Pathologie Biologie, 54(2): 85-93.

DELLA CHIESA, M., SIVORI, S., CASTRICONI, R., MARCENARO, E. and MORETTA, A. 2005. Pathogen-induced private conversations between natural killer and dendritic cells. Trends in Microbiology, 13(3): 128-136.

DE SMEDT, T., PAJAK, B., MURAILLE, E., LASPAGNARD, I. and HEINEN, E. 1996. Regulation of dendritic cell numbers and maturation by lipopolisacharide in vivo. Journal of Experimental Medicine, 184(4): 1413-1424.

DENNEY, J. M., NELSON, E. L., WADHWA, P. D., WATERS, P. D., WATERS, T. P., MATHEW, L., CHUNG, E. K., GOLDBERG, R. L., CULHANE, J. F. 2011. Longitudinal modulation of immune system cytokine profile during pregnancy. Cytokine, 53(2): 170-177.

DENIS, M. and BUDDLE, M. 2008. Bovine dendritic cells are more permissive for Mycobacterium bovis replication than macrophages, but release more IL-12 and induce better immune T-cell proliferation. Immunology and Cell Biology, 86(2): 185-191.

EMERY, D. L., MACHUGH, N. D. and ELLIS, J. A. 1987. The properties and functional activity of non-lymphoid cells from bovine afferent (peripheral) lymph. Immunology, 62(2): 177-183.

GLIDDON, D. R. and HOWARD, C. J. 2002. CD26 is expressed on restricted subpopulation of dendritic cells in vivo. European Journal of Immunology, 32(5): 1472-1481.

HOWARD, C. J., SOPP, P., BROWNLIE, J., KWONG, L. S., PARSONS, K. R. and TAYLOR, G. 1997. Identification of two distinct populations of dendritic cells in afferent lymph that vary in their ability to stimulate T cells. Journal of Immunology, 159(11): 5372-5382.

HOWARD, C. J., BROOKE, G. P., WERLING, D., SOPP, P., HOPE, J. C., PARSONS, K. R. and COLLINS, R. A. 1999. Dendritic cells in cattle: phenotype and function. Veterinary immunology and immunopathology, 72(1): 119-124.

HOPE, J. C., KWONG, L. S., SOPP, P., COLLINS, R. A. and HOWARD, C. J. 2000. Dendritic cells induce $\mathrm{CD}^{+}$and $\mathrm{CD}^{+} \mathrm{T}$ cell responses to Mycobacterium bovis and $\mathrm{M}$. avium antigens in Bacille Calmette Guerin vaccinated and nonvaccinated cattle. Scandinavian Journal of Immunology, 52(3): 285-291.

HEIN, W. R. and GRIEBEL, P. J. 2003. A road less travelled: large animal models in immunological research. Nature Reviews of Immunology, 3: 79-84.

KIRSCHNER, L. S. 2006. Emerging treatment strategies for adrenocortical carcinoma: a new hope. Journal of Clinical Endocrinology and Metabolism, 91(1): 14-21.

LIU, Y.J., 2005. IPC: professional type 1 interferon-producing cells and plasmacytoid dendritic cell precursors. Annual Review of Immunology, 23(1): 275-306. 
MACKENZIE-DYCK, S., ATTAH-POKU, S., JUILLARD, V., BABIUK, L. A., VAN DRUNEN LITTLE-VAN DEN HURK, S. 2011. The synthetic peptides bovine enteric $\beta$-defensin (BNBD) 9 and BNBD 3 are chemotactic for immature bovine dendritic cells. Veterinary Immunology and Immunopathology, 143(12): 87-107.

MAXYMIV, N. G., BHARATHAN, M. and MULLARKY, I. K. 2012. Bovine mammary dendritic cells:a heterogeneous population, distinctfrom macrophages and similar in phenotype to afferentnlymph veiled cells. Comparative Immunology, Microbiology and Infectious Diseases, 35: 31-38.

MANDAL, A. 2014. Dendritic cell life cycle. The news medical life sciences. [Online]. London: Routledge. Avaible at: https://www.news-medical.net/health/Dendritic-Cell-Life-Cycle.aspx [Accessed: 2017, September 17].

MIYAZAWA, K. 2006. Identification of bovine dendritic cell phenotype from bovine peripheral blood. Research in Veterinary Science, 81(1): 40-5.

MCKEEVER, D. J., MACHUGH, N. D., GODDEERIS, B. M., AWINO, E. and MORRISON, W. I. 1991. Bovine afferent lymph veiled cells differ from blood monocytes in phenotype and accessory function. Journal of Immunology, 147(11): 3703-3709.

MCKEEVER, D. J., AWINO, E. and MORRISON, W. I. 1992. Afferent lymph veiled cells prime CD4+ T cell responses in vivo. European Journal of Immunology, 22(12): 3057-3061.

OLDE RIEKERINK, R. G. M., BARKEMA, H. W., KELTON, D. F.and SCHOLL, D. T. 2008. Incidence rate of clinical mastitis on Canadian dairy farms. Journal of Dairy Science, 91: 1366-1377.

PINCHUK, L. M. 2003. Bovine dendritic cells generated from monocytes and bone marrow progenitors regulate immunoglobin production in peripheral blood B cells. Comparative Immunology, Microbiology and Infectious Diseases, 26(4): 233-249.

RAGHUPATHY, R. 2001. Pregnancy: success and failure within the Th1/Th2/Th3 paradigm. Seminars in Immunology, 13(4): 219-227.

REID, E. 2011. Bovine plasmacytoid dendritic cells are the major source of Type I Interferon in response to foot-and-mouth disease virus in vitro and in vivo. Journal of Virology, 85(9): 4297-4308.

ROMANI, N., REIDER, D., HEUER, M., EBNER, S., KAMPGEN, E., EIBL, B., NIEDERWIESER, D. and SCHULER, G. 1996. Generation of mature dendritic cells from human blood. An improved method with special regard to clinical applicability. Journal of Immunological Methods, 196(2): 137-151.

ROMERO-PALOMO, F. et al. 2013. Immunohistochemical detection of dendritic cell markers in cattle. Veterinary Pathology, 50(6): 1099-108.

RYBNER-BARNIER, C. 2006. Processing of the Bovine Spongiform Encephalopathy-Specific Prion Protein by Dendritic Cells. Journal of Virology, 80(10): 4656-4663.

SAlLUSTO, F., CELLA, M., DANIELI, C. and LANZAVECCHIA, A., 1995. Dendritic cells use macropinocytosis and the mannose receptor to concentrate macromolecules in the major histocompatibility complex class II compartment: downregulation by cytokines and bacterial products see comments. Journal of Experimental Medicine, 182(2): 389-400.

SALLUSTO, F. and LANZAVECCHIA, A. 1994. Efficient presentation of soluble antigen by cultured human dendritic cells is maintained by granulocyta/macrophage colony-stimulating factor plus interleukin 4 and downregulated by tumor necrosis factor alpha. Journal of Experimental Medicine, 179(4): 1109-1118.

SATO, S. and FUJITA, S. 2007. Dendritic cells - mature and classification. Allergology Internatinal, 56(3): 183-191.

SEI, J. 2014. Phenotypic, Ultra-Structural, and Functional Characterization of Bovine Peripheral Blood Dendritic Cell Subsets. PlosOne, 9(10): el09273

SYME, R. and GLUCK, S. 2001. Generation of dendritic cells: role of cytokines and potential clinical applications. Transfusion and Apheresis Science, 24(2): 117-124.

STEINMAN, R. M. 1991. The dendritic cell system and its role in immunogenicity. Annual Review of Immunology, 9: 271-296.

SCHUKKEN, Y., POMEROY, B. and SIPKA, A. 2013. New insights into the immunology of the Bovine Mammary Gland. Immunology, 48: 54-60.

SUMMERFIELD, A., AURAY, G. and RICKIN, M. 2015. Comparative dendritic cell biology of veterinary mammals. Annual Review of Animal Biosciences, 3: 533-557.

WERLING, D., PIERCY, J. and COFFEY, T. J. 2006. Expression of TOLL-like receptors (TLR) by bovine antigen-presenting cells-potential role in pathogen discrimination? Veterinary Immunology and Immunopathology, 112(1-2): 2-11.

WERLING, D., HOPE, J. C., CHAPLIN, P., COLliNS, R. A., TAYLOR, G. and HOWARD, C. J. 1999. Involvement of caveolae in the uptake of respiratory syncytial virus antigen by dendritic cells. Journal of Leukocyte Biology, 66(1): 50-58.

ZIEGLER-HEITBROCK, L. 2010. Nomenclature of monocytes and dendritic cells in blood. Blood, 116(16): e74-80. 
